Prof. Roberts-Austen. The question is, as he shows, one of much theoretical interest, and should lead to further experiments.

The author then adopts a method previously used by Spring (Bull. Acad. Roy. Belg., vol. xxviii., I894, p. 40). $\mathrm{He}$ proceeds, after quoting experiments by Ostwald, Demarçay, Pellat, Colson and Russell, to show that alloys may be formed by the vaporisation of certain metals in vacuo at so low a temperature as $50^{\circ} \mathrm{C}$. He

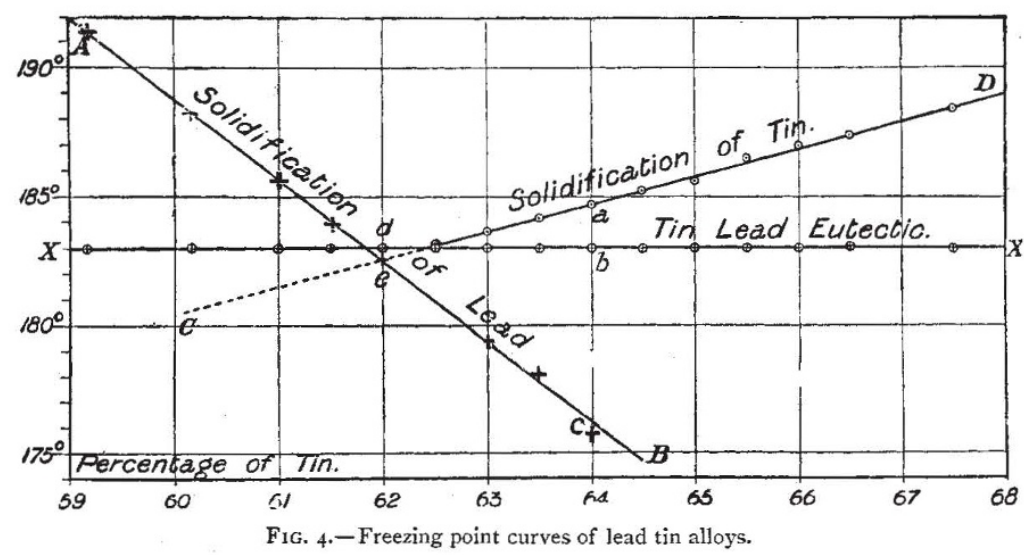

The cost of the building with fittings and new apparatus is estimated at $30,000 l$. Of this sum $17,000 l$. has been subscribed, in one sum of $10,000 l$, one of $5000 l$., and two of $1000 l$. In the plan ample provision for research work has been made. Two large rooms, for instance, are exclusively devoted to spectroscopic work, one of them being arranged to hold a large Rowland grating. It is intended to have at least one room set aside for constant temperature work, and to establish a small plant for the production of low temperatures. An electro-technical laboratory will be added, in which large currents will be available for electric furnaces.

One of the features of the laboratory will be a carefully planned system of ventilation combined with an attempt to exclude dust, as far as possible, from all rooms, and especially from the instrument cases. The plenum system, much used at present, had to be rejected, because it takes up too much valuable basement space, because it is ineffective as regards exclusion of dust, and because the inevitable noise and mechanical shaking due to the fans would have seriously interfered with the work of the laboratory. The architect is Mr. J. W. Beaumont, who, before finally drawing concludes by pointing out that the results given in the present paper reveal additional points of similarity between the behaviour of alloys and that of ordinary saline solutions. He trusts, therefore, that it may be useful as a continuation of his investigation on the "Diffusion of Metals," which formed the subject of the Bakerian Lecture of 1896 .

\section{THE NEW PHYSICAL LABORATORY OF THE OWENS COLLEGE, MANCHESTER.}

THE laboratory of which the foundation-stone has been laid, on the twenty-fifth anniversary of the occupation of the present Owens College buildings, will be the largest and most completely equipped in this country. It stands on a separate plot of ground adjoining the Owens College site, and consists of a main building and a large annexe, the latter being more especially intended for electro-technical work. The principal building is 100 feet long and over 60 wide, and consists of a basement and three stories. The diagram gives the comparison as regards dimensions with some of the principal the plans, was sent by the Council of the Owens College to visit the principal modern laboratories of Germany.

In seconding a vote of thanks to Mr. Henry Simon for laying the foundation-stone, Prof. Schuster gave a short description of the building. In the course of his remarks he said :-

In the general plan of the building I have departed consider ably from that adopted in some of the recent continental buildings. The designer of a laboratory may take either one or other of two opposite views, according as he wishes to differentiate as much or as little as possible between different rooms and between different classes of students. The present tendency is to adopt the former course, and to draw a rigid line of separation between the rooms set aside for elementary and for advanced work. This system is carried out to such an extreme in one of the most recent and, in some respects, most perfect of German laboratories that a separate division with a staircase of its own is provided for the elementary students, who thus can never be brought into contact with their more fortunate colleagues admitted to the main part of the building.

I have adopted the opposite course, for I consider that a free intercourse between different classes of students is of great benefit and educational value. My object has been to throw the students together and not to separate them, so that the
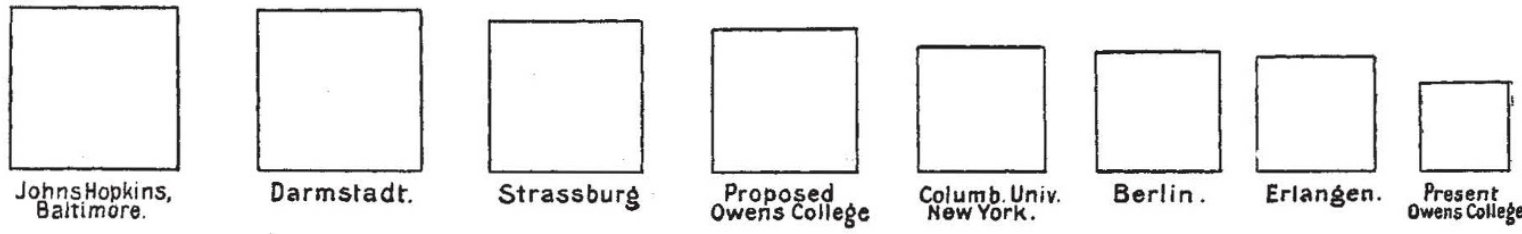

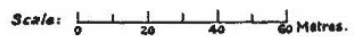

laboratories abroad. The squares represent square area of floor space of the working rooms, i.e. all corridors, cloak-rooms, \&c., are excluded, and the floor space of the different stories added up. It will be seen that the only laboratories materially larger than the proposed building are those of Baltimore and Darmstadt. But provision has been made for future extension, the plot of ground secured by the College being sufficiently large to double, if necessary, the size of the building.

NO. I 5 I 3, VOL. 58] beginner may occasionally see his more advanced colleagues at work, and the latter will have an opportunity to overlook and sometimes to assist their juniors. To some extent, the separation of students is necessitated by the requirements of space and apparatus, but we may do much to minimise instead of exaggerating the division.

Most of the rooms devoted to the highest kind of work are sufficiently large to accommodate several students. In this matter also I have not followed the practice now in fashion, which favours small rooms for single students. It is no doubt 
very convenient to those engaged in original investigations to have undivided command over a space in which they are absolutely undisturbed, and in which they may leave their apparatus secure against interference. But having regard not only to individual convenience but to the general good of the laboratory, my experience leads me to believe that the advantage lies with the older and less luxurious times, when space was valuable and a number of men were forced to work together.

I remember the old laboratory of the great Helmholtz, in which we were about half a dozen students carrying on research work in a room in which each of us had to be satisfiedwith a table.

The Professor used to spend an hour a day with us, conversed with each about the work he was doing, and we could all daily hear him speak and give his advice about a variety of subjects in a way which would have been impossible if we had been shut up in single rooms. We became interested in each other's work, and thus increased our experience and obtained a much broader view of the range of physics. I consider the experience thus gained to have been quite invaluable, but curiously enough the Professor did not himself realise the importance of this mutual intercourse, and a few years later, when he drew up the plans of a new laboratory, he adopted what has with reason been called the principle of solitary confinement, each student having a separate small room assigned to him. The result, I think, showed that the advantage secured by the increased privacy was too dearly paid for. It became impossible for the Professor to make the round of all the rooms each day, he ceased to exercise the same supervision as before; and the students, left to themselves, soon only looked after their own individual interests and lost touch with their comrades.

A great deal of attention has recently been given to the splendidly equipped laboratories of the German polytechnic schools, and the remarkahle development of German industry is not unnaturally ascribed to their influence. But if it be our wish to emulate these laboratories, we should remember that the polytechnic schøol is only one part of a complete system of education which is not possible to copy here. We should inevitably be led to failure if we tried to solve the educational problem of this country by importing one particular type of institution, without regard to the previous training of the students attending it, and what is more difficult to ascertain, their future career or position in life.

We shall do better if we attack the problem by forming a clear idea as to whom we want to educate, and then doing the best we can with the material at our command.

In the industrial life of a country two distinct classes of men are needed. There are in the first place the leaders, on whom all the burden of further pregress will fall. We look to them for future discoveries and inventions, and we must provide them with the proper tools to work their way, and weapons to overcome their obstacles. Though necessarily few in numbers, these men who are specially endowed to serve their country by their intellect and enterprise should receive our first attention. At first sight their education seems easy enough, for what can we do more than lead them up to the highest level of their subject. Yet there is one danger so serious that I believe it lies at the foundation of the distrust with which the greater part of the industrial community still looks upon education. The want of confidence in the teaching profession, which is a national sharacteristic to be reckoned with, because probably not to be cured, has had the effect of establishing a rigid system of teaching and examining, which undoubtedly tends to subdue, if not to kill, individuality. Where any pronounced originality exists, our whole effort should be to foster and develop it. I feel no doubt that the success of our university will entirely depend on the manner in which we allow room for individuality and originality in our courses, while the continued success of our college must depend on the freedom which we claim for individual teaching, even if in special cases the students should be kept out of the university altogether. Far better that a man of original mind should go through life without a a degree, than that he should artificially be driven into the broad path of common-place reasoning. This country has never been wanting in men of the type I am speaking about; they are not brought up in the polytechnic schools of Germany, and never will be brought up by any schools formed on that pattern. Whatever sulccess Germany has achieved is due to the stringent slavery of

$$
\text { NO. I } 5 \text { I 3, VOL. 58] }
$$

its schools, followed and corrected by the absolute freedom of its universities.

I have spoken of two types of students, and the second is no less important than the first. The great majority of men are neither discoverers nor inventors, and they are for that very reason all the more in need of an education which will fit them for their life's work. It is in the instruction of this numerous class of students that we have most to learn, and it is in the intelligent organisation of their teaching that we are behind other countries. It has become a matter of vital importance for this college to offer a thorough training to those men, who, though they may not be leading spirits or originators, yet form a necessary portion of the community and fill responsible positions in our industries. We have taken the first step to-day to remove one of the causes, which has hitherto prevented the physical department attracting these students in sufficient numbers. Our accommodation has till now been hopelessly deficient, but I hope that those who take the trouble to look through'our plans will find that, as regards space and disposition of rooms, we may in future court comparison with any other institution. May I express the hope that the support which we shall get from our friends, will enable us to say the same of our equipment and instrumental appliances. I am, however, quite aware that building and equipment alone will not entirely solve the problem. Certain difficulties of instruction will have to be overcome, which will require not only the co-operation of different departments of the college, but also the help and advice of the manufacturers in whose workshops our students will have to complete their education. I attach the greatest importance to this help, and believe that real progress in what may be called the highest branch of technical education can only be secured by a frequent and sympathetic consultation between the teachers and employers of labour.

One further remark I should like to make in order to remove the objection which I know has been urged against our college, that we wish to unite in it students of different classes, and that, as in Germany, the university instruction should be entirely separated from that of the polytechnic school. But the separation of the two kinds of institutions in that country has not been chosen deliberately to secure the best educational result. It has been the consequence of the very high standard of classical education, which the universities require, and which it was not possible to enforce on the technical students. No one can urge that the literary requirements of our college or of our university are such as unjustly to exclude any one who is fitted to receive a higher technical education. If we want to find a country the educational institutions of which have grown unhampered by historical tradition, we must go to the United States of America, and amongst their universities we shall find some whose success we need not be afraid to emulate. I confess that no other institution has ever impressed me so much as regards efficiency in teaching urganisation and com. pleteness of laboratory organisation as the Cornell University at Ithaca. The class of students visiting that university are nearly akin to those we wish to attract, and if the citizens of Manchester could see the appliances of the physical laboratory: and of its splendidly equipped dynamo house, I think we should have no difficulty here in obtaining the neces sary funds for furnishing appropriately the rooms of our new laboratory.

The extraordinary development of electrical industries in the United States, and the great value which is in that country attached to a university education, may encourage us in the hope that the efforts we are making to extend and improve our electrical teaching will meet with some success.

I hope that the stress I have laid on our intentions regarding electro-technical teaching will not give rise to the impression that we mean to neglect other branches of physics. Our labora. tory will provide arrangements for optical and more particularly spectroscopic work, which will at least be equal to that of any other institution; nor shall we forget the necessary machinery to produce very low temperatures by means of the liquefaction of air.

I had some hope originally to add a small astronomical observatory, but although the plans are such that it could be added at any time, the question of expense has for the present prevented us from carrying out a project for which there was no such pressing necessity. 